\title{
ANÁLISE DOS DISCURSOS REFERENTES À EDUCAÇÃO PERMANENTE EM SAÚDE NO BRASIL (1970 A 2005)
}

\author{
ANALYSIS OF THE DISCOURSES REGARDING CONTINUOUS \\ EDUCATION IN HEALTH IN BRAZIL (1970 TO 2005)
}

\begin{abstract}
Kenia Lara da Silva (DD ${ }_{(0000-0003-3924-2122)^{1}}$, Bruna Dias França iD ${ }_{(0000-0002-1052-6570)}{ }^{1}$, Rita de Cássia Marques (0000-0002-9143-0385) ${ }^{1}$, Juliana Alves Viana de Matos iD ${ }_{(0000-0002-9999-8864)^{1}}$
\end{abstract}

\author{
${ }^{1}$ Universidade Federal de Minas Gerais, Escola de Enfermagem, Departamento de Enfermagem \\ Aplicada, Belo Horizonte, Minas Gerais, Brasil. \\ $<$ kenialara17@gmail.com>
}

Resumo O objetivo foi analisar o processo de construção da Educação Permanente em Saúde, identificando suas transformações, continuidades e rupturas no contexto sócio-histórico da década de 1970 a 2005. Estudo ancorado no referencial teórico-metodológico da Análise Crítica do Discurso. Com base em entrevistas realizadas com representantes da elaboração e gestão da política da Educação Permanente em Saúde, em diferentes momentos históricos, buscamos compreender o contexto, os textos e os atores sociais que compõem o discurso em cada época. Indicam um processo caracterizado por continuidades e rupturas, influenciado pelas ideologias que marcam variações discursivas em cada momento. Deste modo, os discursos da centralidade do trabalho, com suas demandas de profissionalização, qualificação e capacitação, convivem com os discursos da centralidade do sujeito e com suas necessidades de saber e aprender no e com o cotidiano. Compreendese que a Educação Permanente em Saúde no Brasil vem sendo reconfigurada sob determinadas influências políticas, ideológicas e epistemológicas.

Palavras-chave educação continuada; Sistema Único de Saúde; políticas públicas.
Abstract The objective of the study was to analyze the process of establishment of Continuing Education in Health, identifying its transformations, continuities and ruptures in the socio-historic context from the 1970s to 2005. The study is based on the theoretical-methodological framework of the Critical Analysis of Discourse. Based on the interviews made with the representatives of the development and management of the Continuing Education in Health policy in different historic moments, we attempted to understand the context, the texts and the social actors that compose the discourse in each period of time. The results indicate a process characterized by continuities and ruptures, and influenced by the ideologies that mark the discourse variations in each different period. Therefore, the discourses regarding the centrality of the work, with its demands for professionalization, qualification and training, coexist with the discourses regarding the centrality of the individual and with their need to know and learn in and with everyday life. We understand that Continuing Education in Health in Brazil is going through a process of reconfiguration under certain political, ideological and epistemological influences.

Keywords continuing education; Unified Health System; public policies. 


\section{Introdução}

A Educação Permanente em Saúde (EPS) entrou oficialmente para a agenda do Sistema Único de Saúde (SUS), como política pública, no início dos anos 2000 e, desde então, observam-se mudanças nas normatizações específicas que regulamentam o campo.

Apesar da relevância da EPS como política que reafirma os princípios democráticos do SUS e atravessa suas diferentes ações e instâncias, as produções sobre esta temática voltam-se predominantemente para as práticas desenvolvidas nos serviços de saúde, em especial nos hospitais, com poucas análises sobre a formulação política e os discursos produzidos no campo (Sarreta, 2009).

Em 2004, assistimos à promulgação de uma normativa nacional específica que traz a denominação EPS no seu título: a Política Nacional de Educação Permanente em Saúde (PNEPS). Essa política propõe que a EPS seja incorporada pelas instituições de saúde e de educação como um dispositivo capaz de proporcionar a reflexão coletiva e oferecer instrumentos para a transformação do trabalho (Brasil, 2004). Apresenta-se como uma proposta de ação estratégica, capaz de contribuir para a mudança dos processos formativos, das práticas pedagógicas e de saúde e para a organização dos serviços, empreendendo um trabalho articulado entre o sistema de saúde, em suas várias esferas de gestão, e as instituições de ensino (Brasil, 2004).

O Ministério da Saúde (MS), em 2007, reafirmou a PNEPS, por meio da portaria n. 1.996, e estabeleceu novas diretrizes e estratégias objetivando considerar as características de cada região e as necessidades de formação e de desenvolvimento para o trabalho em saúde (Brasil, 2007).

Entende-se que o campo da EPS é um processo de construção contínuo atravessado por diferentes lógicas, a depender dos sujeitos que estão em cena no jogo político, bem como das influências ideológicas e epistemológicas que movem esses sujeitos. Desta forma, as concepções sobre a EPS se refletem nos textos normativos e nas estratégias de operacionalização da política, demarcando, textualmente, as expressões discursivas que conformam as narrativas de cada época. Ademais, os atores sociais e os discursos dominantes na conjuntura nacional e internacional exercem influências na forma como a política, desde sua construção, gestão e concretização, realiza-se nas ações locais.

Frente a esta problemática, questionam-se quais os discursos de EPS produzidos no campo da gestão e da educação no trabalho da década de 1970 até a promulgação de uma PNEPS?

Frente a isso, analisa-se, neste artigo, os discursos sobre EPS no Brasil, como política nacional, identificando suas transformações, continuidades e rupturas no contexto sócio-histórico de 1970 a 2005. 


\section{Metodologia}

O estudo está ancorado no referencial da Análise Crítica do Discurso, desenvolvida por Fairclough (2016). A coleta de dados foi realizada em entrevistas com colaboradores e colaboradoras, tendo como critério de inclusão a atuação no MS em diferentes momentos da política de EPS no país. Nesta direção, os colaboradores e colaboradoras foram identificados como Colaborador 1, que atuou no grupo condutor da política de EPS de 2003 a 2004; Colaborador 2, que atuou em instâncias ligadas à EPS no MS entre 2001 e 2003; Colaborador 3, que atuou diretamente no grupo condução de ações e políticas de EPS, no período de 1985 a 2003 e 2004-2005, além da atuação em períodos posteriores ao recorte da pesquisa; Colaborador 4 e 5, que estiveram no MS entre 2003 e 2005; e Colaborador 6, que atuou nos anos 2002-2003 nas ações ligadas a EPS no MS. Todos os colaboradores identificados aceitaram participar do estudo.

O grupo foi composto por colaboradores que atuaram em distintos momentos da EPS no Brasil, afiliados a diferentes movimentos de militância e que remeteram em seus discursos à trajetória da construção do campo.

As entrevistas foram realizadas presencialmente, com um roteiro semiestruturado que possuía duas perguntas que versavam sobre o contexto de elaboração da política de EPS no Brasil e as questões vigentes no campo do trabalho, da educação e da saúde que influenciaram na construção da política.

O contato com as pessoas entrevistadas foi realizado por meio telefônico e de correio eletrônico. As entrevistas foram realizadas entre 2015 e 2016 e tiveram uma duração média de 1 hora e 20 minutos cada. As entrevistas foram transcritas e submetidas à Análise de Discurso Crítica (ADC) numa abordagem que articula as perspectivas social e linguística na análise, seguindo a Teoria Social do Discurso. O termo discurso é adotado para referir-se ao uso da linguagem como parte da prática social, um modo de ação e representação, social e historicamente situado, em uma relação dialética com a estrutura social (Fairclough, 2016).

A Teoria Social do Discurso trabalha com um modelo que considera três dimensões na análise, compondo um modelo tridimensional compreendido por análise do texto, análise da prática discursiva e análise da prática social (Fairclough, 2001).

A interpretação dos textos compreende um processo complexo, pois o texto pode ser entendido de diferentes maneiras, já que o posicionamento social, conhecimentos, experiências e crenças do(a) leitor(a) resultam em diferentes compreensões. A ADC não advoga uma compreensão particular do texto, mas uma explanação particular, de acordo com a análise realizada pelo leitor(a) (Barros et al., 2016). 
A análise do texto é realizada pelas formas e significados textualmente associados a maneiras de representar, interagir e identificar-se em práticas sociais situadas e que auxiliam no mapeamento das relações dialéticas entre o discursivo e o social. Com isso, possibilita-se a investigação dos efeitos característicos de textos em prática sociais, e vice-versa. Ainda, a prática discursiva é determinada pelos fatores sociais imbricados: os processos de produção, distribuição e consumo do texto, relacionando-os aos aspectos ideológicos e hegemônicos na instância discursiva analisada (Vieira e Resende, 2016).

Nos relatos, destacam-se a prática institucional e a representação de atores sociais, marcadas pela interdiscursividade que retratam as transformações e o pensamento de cada período. Tanto o interdiscurso quanto a representação dos atores sociais são categorias representacionais que permitem perceber o significado que trata da construção (ou representação) de aspectos do mundo via linguagem (Bessa, 2014).

A pesquisa foi aprovada por Comitê de Ética em Pesquisa. Ressalta-se que todas as entrevistas foram precedidas da assinatura do termo de consentimento livre e esclarecido.

\section{Resultados}

\section{Década de 1970}

O percurso histórico da EPS no Brasil foi marcado por diferentes atores, espaços e relações institucionais. Os colaboradores(as) relatam que as primeiras expressões de um 'novo' ${ }^{1}$ modelo educacional para a saúde são citadas desde 1970, com forte influência da Organização Panamericana de Saúde (Opas) cujo objetivo central da formação era o "adestramento" de profissionais de saúde (Paiva, 2015).

(...) Você lembra como é que chamava o programa da Opas, que era lá na Costa Rica, o Pascap: Programa de Adestramento em Salud para o Centro América e Panamá [1978-95], ou seja, o adestramento tá colocado no nome da principal instituição da Opas. [...] foi lá pela década de sessenta, que o Jorge Haddad foi o primeiro diretor, então o Jorge Haddad de alguma forma liberou o pensamento (...) (Colaborador 3)

Nota-se, do ponto de vista discursivo, a força lexical da palavra 'adestramento' presente no nome do Programa configurando a prática social que advêm das experiências fomentadas neste período: adequar ao trabalho. O foco era o processo de preparação de pessoal para a área de saúde numa perspectiva de instrumentalização para o trabalho. Essa ênfase na instrumentalização estava 
em voga com a corrente tecnicista na educação, na qual a(o) professor(a) era mera(o) instrutor(a) e da(o) aprendiz exigia-se apenas o desenvolvimento de habilidades técnicas (Canever, 2013).

Temporalmente, podemos analisar que desde as primeiras iniciativas na década de 1970, que contribuíram para a avaliação das necessidades dos serviços e criação de novos projetos voltados para formação, a EPS esteve imbuída de suprir as necessidades dos serviços. Nesta direção, os achados indicam que nesse período histórico é prevalente o discurso que toma a preparação para o trabalho, 'adestrando' os trabalhadores para as funções que assumiam, demarcando o caráter instrumentalista da educação no campo da saúde.

Os achados indicam que a instrumentalização para o trabalho orientou as propostas de Educação Permanente (EP) por meio do Programa de Desenvolvimento de Recursos Humanos em Saúde da Opas. A expressão 'recursos humanos' presente na denominação do Programa remete às concepções clássicas da administração e reflete a prática da Organização, que tinha como um dos propósitos centrais capacitar pessoal de nível médio e elementar e apoiar a criação de sistemas de desenvolvimento de recursos humanos para saúde nos estados-membros.

A Opas, referenciada nos discursos diretamente ou pelos seus representantes da área de recursos humanos, é ator social importante nos processos de EP, desde 1970, período em que a formação dos trabalhadores foi uma discussão evidente, devido à necessidade de se formar e capacitar profissionais para compor o campo da saúde.

Em novembro de 1973, a Opas e o governo brasileiro, representado pelo MS e pelo Ministério da Educação e Cultura (MEC), firmaram em Brasília um acordo com vistas ao estabelecimento de um programa de desenvolvimento de recursos humanos para a saúde no país (Pires-Alves e Paiva, 2006). Em 1976, com a cooperação da Opas, tem-se como marco a criação do Programa de Preparação Estratégica de Pessoal de Saúde (Ppreps), que visava a formação de pessoal de acordo com as necessidades e possibilidades dos serviços (Paiva, 2015).

Em 1978, a Opas apontou a EP como uma alternativa para atender as necessidades de transformação dos serviços em um processo dinâmico de ensino-aprendizagem, ativo e permanente, destinado a atualizar e melhorar a capacitação de pessoas ou grupos, frente às mudanças científico-tecnológicas (Lino, 2007).

\section{Década de 1980}

Na década de 1980, há uma ruptura na forma de se pensar a formação para os serviços de saúde. Educação com diálogo, não com adestramento. Nesse sentido, a mudança dos termos de 'educação continuada' para 'edu- 
cação permanente' passa a compor o vocabulário do modelo educacional na saúde. Mais que a mudança na nomenclatura, o novo termo representa também uma alteração no eixo orientador do processo educativo, com a intenção de reorientar a capacitação dos trabalhadores no seu cotidiano de trabalho.

(...) Me chamava muita atenção essa ideia de que há o usuário, e há o conjunto dos atores, da cena, do cuidado, da gestão, mas ainda tinha um movimento explícito de inclusão dos diferentes saberes protagonizados pelos outros atores, ok? A aproximação com a produção do Paulo Freire talvez tenha tornado cada vez mais visível isso. (Colaborador 1)

Identifica-se, nos excertos, a representação da figura de Izabel dos Santos para a elaboração de propostas pedagógicas no campo da saúde. Izabel dos Santos foi uma enfermeira idealizadora de iniciativas fundamentais no campo da educação e do trabalho em saúde. Uma dessas iniciativas foi o Programa de Formação em Larga Escala de Pessoal de Nível Médio e Elementar para os Serviços Básicos de Saúde, também conhecido como Projeto Larga Escala (Paiva, 2015). Os discursos apontam também outro importante ator: Paulo Freire.

(...) Quando você coloca a questão da profissionalização da enfermagem, que a Izabel de alguma forma, quer dizer... a Izabel muito centrada na história de como promover um processo de profissionalização do pessoal de enfermagem, não pensando apenas em destrezas, habilidades, mas pensando no resto (...) eu acho que no momento em que o Jorge Haddad traz a reflexão ali da Maria Alice, da Cristina Davini, né, e elas trazem mais do que qualquer outra coisa, o pensamento que naquele momento no Brasil, estava refletido pela Izabel, que está lastreado, lá no pensamento de Paulo Freire. Eu acho que faz uma diferença muito grande, é uma marca que caracteriza essa história da educação. (Colaborador 3)

No excerto, o informante demarca a mudança do pensamento até então vigente nas propostas influenciadas pela Opas para um novo momento, com uma 'diferença muito grande' que marcaria a história dos processos que a EPS começa a trilhar com um referencial problematizador. Nesta direção, a transformação na concepção e na forma dos processos de educação para a saúde são influenciados, ideologicamente, pelo pensamento da educação popular. Depois disso, novos atores sociais são identificados como representantes do discurso da formação.

O Projeto Larga Escala representou uma importante estratégia de EPS no país que tinha como objetivo resolver os 'problemas de recursos humanos'. Foi gestado sob influência do Ppreps e representava o componente Recursos Humanos do recém-criado Programa Nacional de Serviços Básicos de Saúde (Prev-Saúde). ${ }^{2}$ Foi implantado em 1981 em razão da falta de qualificação dos 
trabalhadores dos serviços de saúde e se constituiu num grande marco pelo detalhamento metodológico, voltado para as características de cada trabalhador (Bassinello e Bagnato, 2009).

(...) O Projeto Larga Escala estava dentro do Ppreps era um dos três projetos do Ppreps. Eu acho que esse é um processo de construção muito legal, a gente tinha que pensar sobre ele. O diagnóstico que você faz lá na década de [19]70, quais são os problemas de recursos humanos, não é? Na verdade, eu acho que eles vêm sendo recapeados, reelaborados, mas de certa maneira, quais eram os três projetos do Ppreps? Ppreps é um Programa de Preparação Estratégica do Pessoal de Saúde da Opas, é formação de quadros gestores para o sistema descentralizado no Brasil, que era do programa de formação que sabia que não tinha gente capacitada nos estados para fazer gestão; segundo, integração docente assistencial, e o terceiro, não estou colocando nas ordens, na verdade era o primeiro em termos de orçamento, era da história da profissionalização do pessoal da enfermagem no Brasil (...) (Colaborador 3).

\section{Década de 1990}

Na passagem da década de 1980 para 1990, a construção do SUS representou um marco na redefinição dos rumos da saúde no país. Neste processo, não só foi redefinida a concepção ideológica sobre a saúde como direito de cidadania, mas também foram disparadas importantes iniciativas para sustentar a idealização. Do ponto de vista concreto, a formação de pessoal de saúde ganhou novo sentido, e com ela a EPS reconfigura-se com novos contornos.

A contar da Constituição Federal de 1988 conforma-se um discurso político e estatal, visando a uma garantia dos direitos instaurados na prática da saúde com base nos processos formativos, para o acesso a um serviço de qualidade.

(...) Isso até está na Constituição, uma das coisas que tivemos que nos preocupar não era só com o acesso ao serviço, mas tentar garantir até como ação de Estado e ação do Estado particular do ente, Estado, né... o ente federativo Estado, é a organização desse processo (...) É obrigação do Estado não só promover cuidado no acesso ao serviço mas promover cuidado no acesso aos processos formativos também. E foi isso que a gente assumiu: 'olha isso é problema nosso! Vamos migrar esse processo, vamos articular esse processo.' E claro que fizemos isso junto com o Cosems [Conselho de Secretários Municipais de Saúde] etc. Então os municípios passaram a fazer parte desses processos todos desde o início, né, apoiaram esse processo e aí foi o primeiro movimento de articulação desse movimento (...) (Colaborador 6). 
Uma das atribuições do SUS é ordenar a formação de recursos humanos na área da saúde. Assim, neste momento histórico, o foco se volta para a organização e ordenamento do processo de trabalho, caracterizando uma fase em que a capacitação é palavra de ordem no campo discursivo da educação e formação em saúde.

Os municípios começam a se preparar para assumir a gestão da saúde e também passam a figurar como atores no processo de capacitação, pois era preciso lidar com desafios emergentes da baixa qualificação e formação dos profissionais para lidar com a saúde coletiva (Vasconcelos et al. 2016).

Nesse contexto, em 1991, foi criado o Programa Nacional de Agentes Comunitários de Saúde (Pacs) e, em 1994, o Programa de Saúde da Família (PSF) foi instituído como uma estratégia de reorientação do modelo assistencial. Com a criação desses dois programas, surge a necessidade de formação das/ os profissionais envolvidas/os, desde as/os 'novas/os' Agentes Comunitárias/ os de Saúde (ACSs), até enfermeiras/os, médicas/os, auxiliares e técnicas/os de enfermagem, técnicas/os de higiene bucal e auxiliares de consultório dentário. A EPS não estava alheia a esse processo e o Cosems teve um papel nas definições realizadas na época.

(...) e se faz toda uma discussão então sobre a questão da necessidade de conjuntos trabalhadores, principalmente na área da saúde no mínimo que tivessem nível técnico. E como mexer nessa formação? Já estava começando a surgir a ideia dos institutos. Se estabeleceu ali, se fez as diretrizes curriculares pro técnico, agente comunitário de saúde, o técnico e para o auxiliar em higiene bucal. (Colaborador 5).

O Pacs e, posteriormente, o PSF representaram estratégias fundamentais para a nova lógica da oferta de serviços assistenciais no SUS. Na base, e para garantir o reordenamento da prática nesse programa, a formação de profissionais com novas características era requerida (Simas e Pinto, 2017).

A onda neoliberal que afetou a definição da política no país foi viabilizada com recursos de órgãos internacionais. Isso repercutiu no investimento da saúde, que acabou seguindo novos rumos. Nessa lógica, o financiamento do Banco Mundial nos anos de 1990 foi determinante para o modelo de atenção que se fundava no Brasil (Rizzotto e Campos, 2016).

A decisão por ampliar a Estratégia Saúde da Família era parte do Projeto de Expansão e Consolidação da Saúde da Família (Proesf), projeto estruturante do MS, que recebeu apoio financeiro do Banco Mundial. Nesse projeto, a qualificação dos processos de trabalho era um dos componentes centrais, e esse recurso impulsionou a formação dos Polos de Educação Permanente para o SUS, no mesmo desenho dos Polos de Capacitação em Saúde da Família. 
(...) Mas aí nesse período [2002] fiz parte, pelo [Departamento de Atenção Básica] DAB, do grupo que trabalhou com o Banco Mundial para garantir recursos para os processos voltados à área de recursos humanos, chamava assim: Componente II - Desenvolvimento de Recursos Humanos, tinha três componentes. O Proesf, quando nós levamos a proposta de expansão do número de residências em saúde da família, de financiamento para especializações e para os pólos, tivemos que fazer um trabalho muito grande com o Banco Mundial para eles entenderem o que eram esses polos porque eles não conseguiam entender um arranjo que era virtual na cabeça deles, que não tinha uma estrutura formal (...) (Colaborador 2)

Os Polos de Capacitação, Formação e Educação Permanente em Saúde da Família tinham como foco discutir a melhoria na formação de profissionais do SUS, mais especificamente de profissionais que faziam parte das equipes de saúde da família. Todas as ações passavam pelo MS e eram realizadas em parceria com Instituições de Ensino Superior (IES) do país. A base para a realização do processo de capacitação era a Política de Recursos Humanos para o SUS, relacionada à formação de recursos humanos e desenvolvimento de habilidades, à avaliação dessa formação, à participação ativa da gestão (intersetorial, municipal, estadual, regional e federal) e à descentralização das ações de capacitação destes profissionais. Para tanto, a metodologia empregada buscava reflexões e também a problematização trazendo as necessidades das/ os profissionais para os cursos.

\section{Anos 2000}

Em 2000, foi criado o Projeto de Profissionalização dos Trabalhadores da Área de Enfermagem (Profae), no qual mais de 280 mil trabalhadoras/es de saúde se formaram. Neste período o Profae ofertou cursos de auxiliar de enfermagem, complementação da/o auxiliar de enfermagem para técnica/o de enfermagem e complementação do ensino fundamental (Gottems, Alves e Sena, 2007). A EPS assume, nessa estratégia, o discurso de profissionalização, 'pensando no trabalho, a partir das necessidades do trabalho'

(...) Numa discussão também de como repensar o controle do estado sobre a formação que estava sendo feita no Senac [Serviço Nacional de Aprendizagem Comercial], no Senai [Serviço Nacional de Aprendizagem Industrial], nas instituições formadoras do sistema, e tem o Profae. A maior parte dos trabalhadores de enfermagem foram formados na realidade na época da gente. Toda essa discussão de como fazer um outro tipo de política de educação profissional, fazendo conjuntamente, mas basicamente pensando no trabalho e na formação a partir das necessidades de trabalho conhecendo o conjunto da rede (...) (Colaborador 5). 
Do ponto de vista da prática social, os processos que se iniciam nesta época culminaram com a necessidade de reformulação dos currículos dos cursos da área da saúde, além da ampliação da pós-graduação em saúde da família para favorecer a adequação das/os profissionais ao perfil de atuação no sistema de saúde. Convocam-se as IES no país a assumirem a posição de ator social na EPS.

Concomitantemente, outros processos começam a ser disparados no campo da EPS, tais como: o Programa de Interiorização do Trabalho em Saúde (Pits), em 2001, buscando incentivar a alocação de profissionais da saúde em municípios carentes de recursos sanitários; o Programa de Incentivo às $\mathrm{Mu}$ danças Curriculares nos Cursos de Medicina (Promed), em 2002, com o intuito de adequar as/os profissionais à realidade do sistema de saúde e o projeto de Vivências e Estágios na Realidade do Sistema Único de Saúde (VER-SUS), em 2003. A criação desses programas reafirma o papel do SUS na ordenação da formação de recursos humanos, caracterizando o discurso político-institucional.

[...] a gente foi desenvolvendo linhas específicas de fortalecimento dos diferentes atores, então os estudantes sempre fazem o VER-SUS e uns outros projetos de fortalecimento e ampliação da capacidade de formulação e de possibilidades d'os caras intervirem direto nos processos. Com os professores a gente tentou fazer um projeto com o Fentas [Fórum das Entidades Nacionais de Trabalhadores da Área da Saúde]. Então a gente teve linhas específicas de fortalecimento dos diferentes atores que a gente considerava importantes na produção daquele movimento. Veja: uma aposta, eu diria que é a aposta mais forte da política, era realmente abrir espaço para a produção singular, locorregional dos vários movimentos, que não era só da educação permanente mas da produção do SUS, naquele espaço (...) (Colaborador 4).

(...) E a gente chegou a pensar inclusive que já deveria pensar um processo de educação permanente coordenado pelo ministério de forma mais ampla. Quer dizer, a saúde da família é ótimo, necessário, importante, mas e aí? Tem que começar a pensar antes de fazer isso pelas outras dimensões. Mas, enfim, não foi isso que aconteceu. Durante esse período, a saúde da família tinha uma relevância muito grande dentro do ministério e a questão dos polos ficava ligada especificamente na área da atenção básica, ao [Departamento de Atenção Básica] DAB. (...) A gente foi trabalhar em outras dimensões da formação, mas aí resolvemos algumas coisas importantes lá: Promed, o Pits [Programa de Interiorização dos Trabalhadores de Saúde]. Na verdade, a gente resolveu muita coisa (risos). Não exatamente na sequência, mas em algum momento, e era parecido com o [Programa de Valorização do Profissional da Atenção Básica] Provab, o Promed, o Pro-Saúde etc. Mas tinha essa clivagem, essa separação, quer dizer não era uma proposta ainda... de educação permanente estruturada para o Brasil inteiro (...) (Colaborador 6) 
A necessidade de mudar a atuação das/os profissionais justificava a intensificação das estratégias em que a EPS se concretizava. Proesf, Pits, Profae, Promed, VER-SUS podem ser considerados vitais para garantir a condição da mudança do modelo, uma vez que novas práticas exigiam novas/os e mais profissionais. Havia ainda a necessidade de se conjugar todas essas iniciativas ampliando a sua potência.

Nessa direção, a institucionalização da EP, a começar desse período, teve o esforço de agregar diferentes atores das instituições de ensino, assistência, gestão e controle social para inventar e implementar a educação no trabalho em todos os âmbitos de formação e da capacitação. Neste momento, a EP estava situada no Departamento de Atenção Básica (DAB) do MS, que ordenava o financiamento e a organização dos processos relacionados à Atenção Básica e, consequentemente, da capacitação em Saúde da Família.

A criação da Secretaria de Gestão do Trabalho e da Educação na Saúde (SGTES), em 2003, no Ministério da Saúde, induziu a formulação de políticas de formação, desenvolvimento e gestão dos trabalhadores de saúde. Esta secretaria foi dividida em dois departamentos: o de Gestão da Educação na Saúde (Deges) e o de Gestão e da Regulação do Trabalho em Saúde. O Deges coordenou a inserção da Política de Educação Permanente nos serviços de saúde, proporcionando, assim, a construção de novos perfis profissionais com condições de responder às necessidades de saúde da população (Queiroz, Silva e Oliveira, 2014).

Com a SGTES, institui-se, assim, um espaço governamental para a EP, que migra do DAB para ser orientador de uma Secretaria dentro do MS. Do ponto de vista organizacional, a criação da SGETS representou a definição política institucional do lugar que o trabalho e a educação adquirem no SUS ao ganharem status de secretaria no primeiro escalão do governo. É importante destacar que essa criação acontece em um período do governo democrático popular.

(...) Acho que com a mudança da gestão, houve uma mudança positiva na política, quando é criada a SGTES. Existe uma determinação de valorizar essa área, dos aspectos de formação, de uma política mais estruturante dos processos tanto de formação quanto do trabalho dos profissionais. Então foi um outro contexto político bastante diferente, muito favorável, naquele período para os processos de mudança. O que eu acho que aconteceu foi que houve uma ruptura muito forte. [...] eu acho que houve uma ruptura política muito grande de quem estava antes na implementação do Saúde da Família com quem não estava. Como se o Saúde da Família não fosse o SUS... como se não fosse uma proposta da atenção básica... Então houve um conflito, meio implícito. Não foi uma questão explicitada, mas houve uma situação no começo que foi muito, muito brusca. Então, muitos atores que estavam antes envolvidos com essas propostas acabaram ou saindo ou sendo saídos dos processos e foram também procurando outras coisas porque a vida roda [...] (Colaborador 2). 
Em 2004, é aprovada a portaria GM/MS n. 198 que institui a Política Nacional de Educação Permanente em Saúde (PNEPS), como uma estratégia do SUS para a formação dos trabalhadores deste campo. Segundo esta portaria, a EPS é definida como um processo de aprendizagem, no qual o aprender e o ensinar fazem parte do cotidiano do trabalho (Brasil, 2004).

Para a condução da PNEPS, foram implantados os Polos de Educação Permanente em Saúde, uma instância de gestão com base no quadrilátero da formação: ensino, gestão, atenção, controle social. Esse período foi permeado por muitas disputas.

(...) Eu não tinha muita assim... não era no cotidiano... Eu participei um pouco do debate sobre e a insuficiência dos Polos [de Saúde da Família] porque na verdade a transição foi dos Polos para as rodas. A estratégia eram Polos e, depois, quando essa estratégia é quebrada, ela se transforma em rodas ${ }^{3}$. Mas rodas que precisavam ter uma certa objetivação. Então, o que eu acho que aconteceu nesse período foi uma deliberação de primeiro ampliar muito o número de atores e a diversificação dos atores e isso é o que estava na estratégia de transformação... Claro que teve um conjunto de formalidades que ela precisou ser implementada porque tinha que, de uma certa forma, objetivar essa quebra de instituído. Porque tinha que ter meta, tinha que ter... Então teve um conjunto de coisas que foi implementado um pouco para aproximação com a regra geral. (...) Então acho que foi um período curto pra ir organizando a transição. Então, certamente, há divergências internas no Ministério da Saúde (...) (Colaborador 1).

Nesse período, uma série de estratégias foram adotadas para garantir a operacionalidade da EPS, tais como o VER-SUS, a formação de formuladores de políticas, residências médica e multiprofissional, educação popular e educação nos hospitais de ensino. Essas estratégias configuraram o arcabouço operativo para capilarizar a EPS na formação, na atenção, na gestão e no controle social.

(...) no geral, então, tinha os atores que trabalharam, defenderam muito fortemente. (...) eles estavam defendendo isso: o VER-SUS, Residência Multiprofissional, a [Educação a Distância] EAD. Enfim, eram todos elementos importantes nesse processo. Então, eu acho que tem um desconforto, para mim a educação permanente tem que ficar muito mais perto da gestão do que de algum lugar que pensa capacitação, entendeu? (Colaborador 4)

Todas as ações nesse período reforçavam a necessidade de mudar a formação, discurso que passou a compor o repertório da EP. Nesse contexto, as instituições de ensino são convocadas a implantarem processos de reformas, assumindo a representação de ator social fundamental para a ocorrência da 
EP. Tal análise se assenta na evidência de que as estratégias elencadas desde este período tiveram estas instituições como partícipes obrigatórios.

Contudo, para dentro das instituições formadoras também era preciso rever a formação, e as respostas dessas instituições foram tardias e dependeram de outros disparadores. Nesta direção, foram criados o Programa Nacional de Reorientação da Formação Profissional em Saúde (Pro-Saúde) e o Programa de Educação pelo Trabalho para a Saúde (PET-Saúde), programas interministeriais, para incentivar mudanças curriculares nos cursos de graduação na área da saúde.

A indução financeira proporcionada pelo Pro-saúde e PET reforçava o discurso político-institucional da necessidade de mudança da formação e a posição ativa do ator Estado brasileiro, por meio dos Ministérios da Saúde e Educação, na ordenação da formação. A gestão adquire, nos discursos, a representação ativa de ator social responsável por planejar e conduzir as atividades.

Em 20 de agosto de 2007, a portaria GM n. 1996 substitui a designação dos polos pelas Comissões de Integração de Ensino e Serviço (CIES). Nessa mesma portaria, art. $2, \S 1^{\circ}$, encontra-se o Plano de Ação Regional de Educação Permanente em Saúde (Pareps), elaborado pelos colegiados de gestão regional, com o intuito de considerar as especificidades locais (Brasil, 2007).

(...) Então algumas ações precisam, é compreensível você não centralizar, mas isso passou a ser feito com muito mais intensidade eu acho (...) Quer dizer, muito centralizado no Ministério(...) Então aquela ideia de que você construía isso regionalmente, construía isso localmente e o recurso era definido em função do Pareps, que se construía regionalmente, não deixou de acontecer (...) (Colaborador 6)

A perspectiva cartorial foi destacada, com a criação de um conjunto de estruturas institucionais-normativas para operar a política, reafirmando a força discursiva do ordenamento da formação pelas instâncias de gestão.

(...) Muito difícil. Então, as áreas técnicas continuam tendo as suas caixinhas... continuam vendo só as suas necessidades. E, na direção da Escola de Saúde Pública, eu tentei reavivar a política de integração ensino serviço para poder retomar de novo um pouco de discussão em torno da educação permanente. Fui barrada literalmente. (...) O diretor ao qual eu estava subordinada me disse textualmente “Não quero polos..." aí eu falei “- Então vamos pensar em núcleos, uma coisa mais lógica..." “- Não quero núcleos" ele disse (...) a única coisa que eu consegui fazer foi ativar a CIES Estadual, para poder pelo menos não deixar morrer o processo (...) (Colaborador 2). 
(...) O secretário é o primeiro escalão. É... e enfim eu estava falando um pouco da questão da conformação dos Pareps, isso passou a ser feito regionalmente junto com os municípios. Então tinha aquele recurso que o ministério disponibilizava periodicamente, anualmente, e isso já era pactuado em fazer a educação com o Cosems, quer dizer a partir da discussão dos Pareps em cada uma das regiões isso definiu um certo valor para cada, para cada região em função das propostas de capacitação que eles iriam apresentar não é? (...) (Colaborador 6)

Mais recentemente, a criação do Programa Mais Médicos, em 2013, contribuiu para o fortalecimento da política de EPS, fundamentada na integração ensino-serviço. Essa expressão, que baseada nos programas de indução de mudança na formação dos profissionais de saúde ganha maior significado no repertório textual da EPS no Brasil, expressa o lugar que cada um dos lócus, ensino e serviço, assume nesta nova perspectiva: de articuladamente formularem as demandas.

Os resultados indicam, ainda, a tendência da EPS nas residências multiprofissionais, pois proporciona o aprendizado, com base no campo de trabalho, resgatando as noções textuais da capacitação e qualificação da educação profissional.

\section{Os (inter) discursos da educação permanente em saúde}

A análise do corpus empírico permitiu identificar os discursos que retratam o processo histórico da construção e reconstrução da EPS no Brasil. O discurso da centralidade do trabalho (com suas variações de adestramento, instrumentalização e educação profissional para atender as demandas dos serviços) convive, interdiscursivamente, com o discurso da centralidade dos sujeitos (expresso na educação popular e na identificação das necessidades dos sujeitos para o processo de aprender). No primeiro, o trabalho adquire centralidade e conforma as ordens do discurso que marcam a EPS como o processo educativo que se opera no trabalho, pelo trabalho, para o trabalho.

Importa ressaltar que na visão tridimensional, a dimensão textual (com os vocábulos que marcam cada período histórico), a dimensão discursiva (expressos na representação social dos atores que são evocados) e a dimensão da prática social (com as matrizes sociais do discurso com seus efeitos ideológicos e políticos) estão dialeticamente relacionados. Assim, por exemplo, o uso da palavra adestramento associada à Opas como ator social no processo de EPS na década de 1970 indica a concepção hegemônica neste período de que as/os trabalhadoras/es precisavam ser 'dominadas/os e controladas/os' para exercerem determinadas funções. 
Não obstante, o discurso da instrumentalização para o trabalho com suas variações de profissionalização, capacitação, qualificação encontra na Educação Profissional a matriz ideológica que orienta as práticas sociais neste campo.

No discurso da centralidade dos sujeitos, ainda que o trabalho seja o contexto no qual a EPS acontece, foi possível também evidenciar as matrizes ideológicas que conformam a EPS atravessada pelos princípios da educação popular. Assim, não só o trabalho adquire centralidade, mas é possível visualizar que são incorporadas as perspectivas dos sujeitos (ao problematizar a realidade em que estão inseridos) e do seu contexto como disparadores dos processos de EP. É a tradução do pensamento de um processo que deve acontecer no cotidiano, como lócus de aprendizagem, problematizado e afetado pelas questões que atravessam o agir de diferentes atores na saúde: gestores, trabalhadores, professores, estudantes e usuários.

Por fim, identifica-se o discurso político-institucional do ordenamento e mudança da formação que reflete a afirmação da matriz ideológica do Estado como regulador na formulação das políticas públicas no campo da saúde e da educação. Nessa perspectiva, os atores sociais que adquirem representação ativa nas estratégias de EP são as instâncias de gestão, em especial, na figura dos municípios e da SGTES. Evidencia-se a força discursiva do ordenamento da formação como marco que se reflete nos mecanismos institucionais-normativos de operar a política.

Os discursos de EPS, em cada momento histórico, revelam-se também nas estratégias propostas. Assim, foi possível identificar desde os modos mais formais de se realizar a EPS com os cursos, as certificações, as qualificações - incluindo-se recentemente as residências - até as estratégias que pressupõem mais liberdade de criação como as rodas. Importa ressaltar que o caráter interdiscursivo da regulação do Estado atravessa todas as estratégias com a instituição de mecanismos que se propõem a estimular, organizar, financiar ou mesmo induzir a EPS, ordenando o processo.

Neste cenário, as IES como o ator social na construção da EPS no Brasil adquirem importância estratégica, ora como lócus da concretização dos processos dando-lhes o caráter formal da educação profissional, ora como espaços nos quais também se demanda EP, seja para formar 'novos' profissionais de saúde ou mudar a lógica do ensino, requerendo novos perfis de docentes.

Associada a essas perspectivas, analisa-se a representação que determinados atores assumiram ao longo da trajetória. Figuras ligadas à Opas (Jorge Haddad, Maria Cristina Davini, Izabel dos Santos) e Paulo Freire são citados como atores de destaque por conduzirem ou influenciarem ideologicamente os processos de EPS no Brasil. Não obstante, tal representação é fruto das posições sociais que estes atores ocupavam na formulação da política nacional, bem como da expressão dos seus pensamentos na matriz social e nas ordens dos discursos. 
Na trajetória histórica da EPS no Brasil foram muitas as disputas. Foi possível identificar a vulnerabilidade às mudanças de gestão, desde a sua assunção como foco de uma secretaria na instância do governo federal até a priorização do seu objeto nas propostas de financiamento nacionais e internacionais.

\section{Considerações Finais}

Conclui-se que a EPS apresenta um dinamismo que depende do contexto político, histórico e social para se concretizar. Para as/os agentes participantes desse trabalho, a EPS sempre esteve num movimento constante dentro e fora do MS e não se trata, portanto, de um objeto estático, perdido no tempo e instaurado pela promulgação de uma política nacional.

Os achados deste estudo indicam o contexto de influências, determinado inicialmente por órgãos internacionais, mas também pelas demandas nacionais frente à estruturação do SUS e da necessidade de mudanças no modelo de assistência em saúde. Esse caminho é marcado por rupturas nas quais as mudanças na gestão determinam a expressão do campo da EPS.

Por outro lado, identificaram-se também as transformações ideológicas que marcaram a EPS nos períodos estudados desde a educação profissional e a educação popular como campos de conhecimento na educação, bem como o modelo de regulação do Estado na conformação das políticas.

Foi possível concluir que a EPS apresenta uma trajetória que se constrói, influenciada pelos discursos dominantes no cenário nacional e institucional. Com isso podemos compreender que a EPS vem sendo recriada e reconfigurada sob determinadas influências políticas, ideológicas e epistemológicas.

\section{ANÁLISIS DE LOS DISCURSOS REFERENTES A LA EDUCACIÓN PERMANENTE EN SALUD EN BRASIL (1970 A 2005)}

Resumen El objetivo del estudio fue analizar el proceso de construcción de la Educación Permanente en Salud, identificando sus transformaciones, continuidades y rupturas en el contexto sociohistórico entre las décadas de 1970 a 2005. Estudio basado en el marco referencial teórico-metodológico del Análisis Crítico del Discurso. Con base en entrevistas realizadas con representantes de la elaboración y gestión de la política de Educación Permanente en Salud, en diferentes momentos históricos, buscamos comprender el contexto, los textos y los actores sociales que componen el discurso en cada época. Los resultados indican un proceso caracterizado por continuidades y rupturas, influenciado por las ideologías que marcan variaciones discursivas en cada momento. De este modo, los discursos de la centralidad del trabajo, con sus demandas de profesionalización, cualificación y capacitación, conviven con los discursos de la centralidad del sujeto y sus necesidades de saber y aprender de y con lo cotidiano. Se deduce que la Educación Permanente en Salud en Brasil viene siendo reconfigurada bajo determinadas influencias políticas, ideológicas y epistemológicas.

Palabras clave educación continua; Sistema Único de Salud; políticas públicas. 


\section{Colaboradores}

Todas as autoras contribuíram igualmente para elaboração do artigo.

\section{Financiamento}

Fundação de Amparo à Pesquisa do Estado de Minas Gerais e Conselho Nacional de Desenvolvimento Científico e Tecnológico EDITAL 14/2013 Programa de Pesquisa para o SUS - PPSUS - Processo APQ 03466-13. Conselho Nacional de Desenvolvimento Científico e Tecnológico, Chamada MCTI/CNPq/MS - SCTIE - Decit No 08/2013 - Processo 401345/2013-0.

\section{Notas}

${ }^{1}$ Destacamos aqui o novo entre aspas pois desde a década de 1950 é possível identificar iniciativas caracterizadas como educação e treinamento para o trabalho em saúde no Brasil, inicialmente pelo Serviço Especial de Saúde Pública e mais tarde com a própria Opas, mas somente a partir da década de 1970 que se instituem movimentos mais consolidados nesta direção.

2 O Prev-Saúde se constituiu em uma proposta de articulação entre as áreas de saúde pública e os serviços de assistência médica. No componente de recursos humanos, visava promover a formação e emprego preferencial de pessoal generalista. Da mesma forma, pretendia-se ampliar a preparação de um contingente de trabalhadores auxiliares nos níveis médio e elementar. Visava também promover as condições institucionais e a formação em nível gerencial, de modo a permitir um melhor planejamento e gestão do trabalho em saúde.

3 As rodas de EPS representam a metodologia sugerida em 2002, para provocar o debate e a construção coletiva.

\section{Referências}

BASSINELLO, Greicelene A. H.; BAGNATO, Maria H. S. Os primórdios do Projeto Larga Escala: tempo de rememorar. Revista Brasileira de Enfermagem, Brasília, v. 62, n. 4, p. 620626, ago. 2009. Disponível em: <http://www. scielo.br/scielo.php?script=sci_arttext\&pi $\mathrm{d}=$ S0034-71672009000400022 > . Acesso em: 20 abr. 2018.
BARROS, Solange M.; VIEIRA, Viviane; RESENDE, Viviane M. Realismo crítico e análise de discurso crítica: hibridismos de fronteiras epistemológicas. Polifonia, Cuiabá-MT, v. 23, n. 33, p. 11-28, jan./jun., 2016.

BESSA, Décio. Linguagem e situação de rua. In: MAGALHÃES, Izabel; CAETANO, Carmem 
J. M.; BESSA, Décio. Pesquisa em análise de discurso crítica. Covilhã: Livros LABCOM, 2014. p. 25-52.

BRASIL. Ministério da Saúde. Portaria GM/ MS n 198, de 13 de fevereiro de 2004. Institui a Política Nacional de Educação Permanente em Saúde como estratégia do Sistema Único de Saúde para a formação e o desenvolvimento de trabalhadores para o setor e de outras providências. Brasília: Ministério da Saúde, 2004.

BRASIL. Ministério da Saúde. Portaria GM/ MS n. 1.996, de 20 de agosto de 2007. Dispõe sobre as diretrizes para a implementação da Política Nacional de Educação Permanente em Saúde e dá outras providências. Brasília: Ministério da Saúde, 2007.

CANEVER, Bruna P. et al. Tendências pedagógicas na produção do conhecimento em educação em enfermagem do estado de São Paulo. Revista Brasileira de Enfermagem, Brasília, v. 66, n. 6, p. 935-941, dez. 2013. Disponível em: <http:// dx.doi.org/10.1590/S0034-71672013000600019>. Acesso em: 20 abr. 2018.

FAIRCLOUGH, Norman. Discurso e mudança social. Brasília: Editora UnB, 2001.

FAIRCLOUGH, Norman. Discurso e mudança social. 2. ed. Brasília: Editora UnB, 2016.

GOTTEMS, Leila B. D.; ALVES, Elioenai D.; SENA, Roseni R. A enfermagem brasileira e a profissionalização de nível técnico: análise em retrospectiva. Revista Latino-Americana de Enfermagem, Ribeirão Preto, v. 15, n. 5, p. 1.033-1.040, out. 2007. Disponível em: <http:// dx.doi.org/10.1590/S0104-11692007000500023>. Acesso em: 15 jun. 2018.

LINO, Mônica M.; BACKES, Vânia M. S.; SCHMIDT, Sandra M. S. et al. A realidade da Educação Continuada na Enfermagem nos Serviços Públicos de Saúde de Florianópolis. Online Brazilian Journal of Nursing, Florianópolis - SC, v. 6, n. 0, 2007.

PAIVA, Carlos H. A. Izabel dos Santos e a formação dos trabalhadores da saúde. Ciência e Saúde Coletiva, Rio de Janeiro, v. 20, n. 6, p. 1.785-
1.793, Jun. 2015. Disponível em: <http://dx.doi. org/10.1590/1413-81232015206.00132015>. Acesso em: 18 mar. 2018.

PIRES-ALVES, Fernando, PAIVA, Carlos H. A. História da cooperação técnica OPAS-Brasil em Recursos Humanos para a Saúde (1975-1988). Rio de Janeiro: Fiocruz, 2006.

QUEIROZ, Danielly M.; SILVA, Maria R. F.; OLIVEIRA, Lúcia C. Educação Permanente com Agentes Comunitários de Saúde: potencialidades de uma formação norteada pelo referencial da Educação Popular e Saúde. Interface (Botucatu), Botucatu, v. 18, supl. 2, p. 1.199-1.210, 2014. Disponível em: <http://dx.doi.org/10.1590/180757622013.0303>. Acesso em: 6 jan. 2018.

RIZZOTTO, Maria L. F.; CAMPOS, Gastão W. S. O Banco Mundial e o Sistema Único de Saúde brasileiro no início do século XXI. Saúde e Sociedade, São Paulo, v. 25, n. 2, p. 263-276, Jun. 2016. Disponível em: <http://dx.doi.org/10.1590/ S0104-12902016150960>. Acesso em: 6 jan. 2018.

SARRETA, Fernanda O. Educação permanente em saúde para os trabalhadores do SUS. São Paulo: Cultura Acadêmica, 2009.

SIMAS, Paloma R. P.; PINTO, Isabela C. M. Trabalho em saúde: retrato dos agentes comunitários de saúde da região Nordeste do Brasil. Ciência e Saúde Coletiva, Rio de Janeiro, v. 22, n. 6, p. 1.865-1.876, jun. 2017. Disponível em: <http:// dx.doi.org/10.1590/1413-81232017226.01532017> . Acesso em: 8 fev. 2018.

VASCONCELOS, Michele F. F. et al. Entre políticas (EPS - Educação Permanente em Saúde e PNH - Política Nacional de Humanização): por um modo de formar no/para o Sistema Único de Saúde (SUS). Interface (Botucatu), Botucatu, v. 20, n. 59, p. 981-991, dez. 2016. Disponível em: $<$ http://www.scielo.br/scielo.php?script=sci arttext\&pid=S1414-32832016000400981\&lng $=e n \& n r m=i s o>$. Acesso em: 18 Set. 2018.

VIEIRA, Viviane; RESENDE, Viviane $\mathrm{M}$. Análise de discurso (para a) crítica: o texto como material de pesquisa. 2. ed. Campinas: Pontes, 2016. 